al-Kimiya, Vol. 6, No. 1 (28-31) Juni 2019/Syawwal 1440 H

\title{
ANALISIS KADAR TIMBAL PADA SEDIAAN MASKARA DARI PASAR LOKAL DI BANDUNG
}

\author{
FENTI FATMAWATI ${ }^{1}$, AiYi ASNAWAI ${ }^{1}$, DAN SigIt ERAWAN ${ }^{1}$
}

${ }^{1}$ Program Studi Farmasi, Sekolah Tinggi Farmasi Bandung

Jl. Soekarno-Hatta No.754, Cipadung Kidul, Panyileukan, Kota Bandung

*alamat email korespondensi: fenti.fatmawati@stfb.ac.id

\begin{abstract}
Informasi Artikel Abstrak/Abstract
Riwayat Naskah :

Diterima pada 8

April 2019

Diterima setelah

direvisi pada 4 Juli

2019

Maskara adalah salah satu sediaan kosmetik yang banyak digunakan oleh wanita untuk memperindah riasan mata. Maskara dapat dibeli secara bebas di pasar dan beberapa produk kosmetik ini tidak terdaftar sehingga berisiko terkontaminasi oleh logam berat yang dapat membahayakan tubuh manusia. Kandungan logam berat dalam kosmetik biasanya sangat kecil. Salah satu logam berat yang berbahaya bagi tubuh manusia adalah timbal, yang dapat Diterbitkan pada 5 Juli 2019 dianalisis menggunakan spektrofotometer serapan atom pada panjang gelombang $283 \mathrm{~nm}$. Tujuan dari penelitian ini adalah untuk mengetahui kadar $\mathrm{Pb}$ pada maskara merk terkenal dan merk yang tidak terkenal yang beredar di pasar lokal Kiaracondong Bandung. Penentuan kadar timbal dalam sampel dilakukan setelah persiapan sampel dan validasi metode. Hasil analisis yang dilakukan pada validasi metode seperti linearitas, batas deteksi, batas kuantitasi, akurasi dan presisi semuanya memenuhi persyaratan validasi. Kadar timbal yang ditemukan dalam sampel maskara merek terkenal adalah $7,1729 \mathrm{mg} / \mathrm{L}$ dan $149,7781 \mathrm{mg} / \mathrm{L}$ sedangkan pada sampel maskara merek tidak terkenal adalah $15,6118 \mathrm{mg} / \mathrm{L}$ dan 9,2827 mg/L. Satu dari dua sampel kosmetik merek terkenal positif mengandung kadar timbal yang melebihi batas

Kata Kunci: SSA; maksimum kontaminasi yang ditetapkan BPOM RI tahun 2011, yaitu melebihi $20 \mathrm{mg} / \mathrm{L}$,

Kosmetik; Regulasi; Timbal; Validasi. sedangkan 2 sampel kosmetik dari merek tidak terkenal mengandung kadar timbal yang masih dalam batas aman.
\end{abstract}

Keywords: AAS;

Cosmetics;

Mascara is one of the cosmetic preparations that are widely used by women to beautify eye Regulations; Lead; Validation. makeup. Mascara can be purchased freely on the market and some of these cosmetics products are not registered, so they are at risk of being contaminated by heavy metals that can harm to the human body. The heavy metal content in cosmetics is usually very small. To find out the lead levels, we use atomic absorption spectrophotometry with a wavelength of 283 $\mathrm{nm}$. The purpose of this study was to determine Pb levels in mascara circulating in the Kiaracondong local market, Indonesia. Determination of lead levels in samples was carried out after sample preparation and method validation. The results of the analysis carried out on method validation such as linearity, detection limits, quantitation limits, accuracy and precision all meet the validation requirements. The lead levels found in famous brand mascara samples were $7.1729 \mathrm{mg} / \mathrm{L}$ and $149.7781 \mathrm{mg} / \mathrm{L}$ while in the unfamous brand mascara samples were $15.6118 \mathrm{mg} / \mathrm{L}$ and $9.2827 \mathrm{mg} / \mathrm{L}$. From the measurement of lead levels in mascara originating from the kiaracondong local market, 2 samples were famous brand and 2 samples that were unfamous brand positively contained heavy metals. One of the two positive cosmetics samples from famus brand contains lead levels that exceed the maximum limit of contamination of BPOM RI in 2011, which is stated not more than $20 \mathrm{mg} / \mathrm{L}$, whereas 2 positive cosmetics samples that were unfamous brand still within safe limits.

\section{PENDAHULUAN}

Saat ini berbagai jenis kosmetik tersedia di pasaran dan digunakan sebagai kebutuhan seharihari. Secara kimia kosmetik terdiri dari bahan aktif yang disesuaikan dengan kegunaannya, bahan kimia ini dapat berupa logam atau nonlogam [1]. Beberapa produk kosmetik mengandung logam berat seperti timbal, arsenik, merkuri, kobalt, dan nikel yang digunakan sebagai bahan dasar [2]. Penelitian telah membuktikan bahwa logam berat yang terkandung dalam kosmetik saat digunakan dapat menyebabkan beberapa gangguan kulit. Konsumen memiliki hak untuk mendapatkan jaminan keamanan dalam penggunaan kosmetik. Di beberapa negara penggunaan logam berat telah dilarang. Secara umum, kandungan logam berat dalam kosmetik kecil, sehingga dampak atau efek yang ditimbulkannya tidak langsung dirasakan oleh pengguna. Arsen ditemukan di alam dalam jumlah yang sangat kecil namun memiliki tingkat toksisitas yang tinggi [3]. Kadmium ditemukan di alam dalam bentuk mineral yang bereaksi dengan elemen lain seperti oksigen, klorin atau sulfur. 
Paparan kadmium terhadap kulit dapat menyebabkan iritasi dermatitis.

Timbal adalah salah satu logam berat yang sering ditemukan dalam kosmetik. Timbal dapat ditemukan hampir di semua bagian lingkungan. Food and Drug Administration telah merekomendasikan bahwa produk-produk kosmetik bibir dan kosmetik yang diaplikasikan secara eksternal tidak mengandung timbal lebih dari $10 \mathrm{mg} / \mathrm{L}$ sebagai pengotor [4]. Jumlah timbal maksimum dalam peraturan BPOM telah ditetapkan sebesar $20 \mathrm{mg} / \mathrm{L}$ [5]. Gejala yang muncul ketika kita terpapar timbal antara lain sakit perut, kram perut, perilaku agresif, sembelit, masalah tidur, sakit kepala, lekas marah, kehilangan keterampilan perkembangan pada anak-anak, kehilangan nafsu makan, kelelahan, tekanan darah tinggi, mati rasa atau kesemutan di ekstremitas, kehilangan memori, anemia, disfungsi ginjal [6]. Tujuan dari penelitian ini adalah untuk mengetahui keberadaan kandungan logam berat timbal dalam kosmetik maskara dan menentukan jumlah kadar timbal di berbagai merek kosmetik dengan metode spektrofotometri serapan atom.

\section{EKSPERIMEN}

Penelitian ini membahas analisis kadar timbal $(\mathrm{Pb})$ pada berbagai merek kosmetik di pasar lokal Kiaracondong Kota Bandung menggunakan Spektrofotometri Serapan Atom. Tahapan yang dilakukan dalam penelitian meliputi persiapan sampel, validasi metode dan penentuan kadar timbal.

\section{Material}

Bahan yang digunakan pada penelitian ini yaitu $\mathrm{HCl}$ p.a, $\mathrm{HNO}_{3} 0,1 \mathrm{~N}$ p.a, $\mathrm{Pb}\left(\mathrm{NO}_{3}\right)_{2}$ p.a, akua DM, maskara yang bermerk terkenal (FB1, FB2, FB3), dan merk tidak terkenal (UFB1, UFB2, UFB3).

\section{Instrumentasi}

Instrumentasi yang digunakan adalah Spektofotometer Serapan Atom (SSA) merek AA 6300 Shimadzu, Jerman.

\section{Prosedur}

\section{Penyiapan Sampel}

Sampel dikumpulkan, yaitu merek terkenal (FB1, FB2, FB3) dan merek tidak terkenal (UFB1, UFB2, UFB3).

\section{Destruksi Kering}

Sampel dipanaskan dengan menggunkan oven pada suhu $105^{\circ} \mathrm{C}$ selama 2 jam lalu didinginkan \pm 15 menit. Setelah itu, dipanaskan kembali dalam tanur dengan suhu $600^{\circ} \mathrm{C}$ selama 8 jam lalu didinginkan \pm 15 menit. Selanjutnya, sampel ditambahkan dengan $\mathrm{HCl} 10 \mathrm{~N}$ dan $\mathrm{HNO}_{3}$ $0,1 \mathrm{~N}$ sebanyak $3 \mathrm{~mL}$ hingga sampel terendam dan selanjutnya ditambahkan dengan aquabides. Sampel dipanaskan kembali diatas hotplate sampai larutan abu menyusut menjadi $\pm 3 \mathrm{~mL}$. Larutan tersebut disaring dan dimasukan ke dalam labu ukur $25 \mathrm{~mL}$ lalu ditambahkan aquabides sampai tanda batas. Larutan sampel tersebut siap dianalisis [7].

\section{Pembuatan Larutan Standar}

Larutan induk $\mathrm{Pb}\left(\mathrm{NO}_{3}\right)_{2} 1000 \mathrm{mg} / \mathrm{L}$ dipipet sebanyak $2,5 \mathrm{~mL}$ lalu dimasukkan ke dalam labu ukur $25 \mathrm{~mL}$. Larutan $\mathrm{HNO}_{3}$ 0,5 M ditambahkan hingga batas ukur sehingga diperoleh konsentrasi $100 \mathrm{mg} / \mathrm{L}$. Larutan induk $\mathrm{Pb}\left(\mathrm{NO}_{3}\right)_{2} 10 \mathrm{mg} / \mathrm{L}$ dibuat dari larutan $\mathrm{Pb}\left(\mathrm{NO}_{3}\right)_{2} 100 \mathrm{mg} / \mathrm{L}$ dengan mempipet sebanyak $5 \mathrm{~mL}$, lalu dimasukkan ke dalam labu ukur $50 \mathrm{~mL}$, aquades ditambahkan hingga batas ukur. Larutan induk $\mathrm{Pb}\left(\mathrm{NO}_{3}\right)_{2} 10$ $\mathrm{mg} / \mathrm{L}$ dipipet sebanyak 0,$5 ; 1 ; 1,5 ; 2 ; 2,5$ dan 3 $\mathrm{ml}$ lalu masing-masing larutan dimasukkan ke dalam enam buah labu ukur $10 \mathrm{~mL}$ yang berbeda kemudian diencerkan dengan aquabides sampai tanda batas dan dihomogenkan sehingga diperoleh larutan dengan konsentrasi 0,$5 ; 1 ; 1,5 ; 2 ; 2,5$ dan $3 \mathrm{mg} / \mathrm{L}$. Larutan standar timbal pada masingmasing konsentrasi tersebut diukur serapannya menggunakan SSA dan hasil absorbansinya diplotkan ke dalam kurva kalibrasi [7].

\section{Penentuan Kadar Timbal Pada Sampel}

Hasil destruksi larutan sampel dianalisis menggunakan SSA pada panjang gelombang 283 $\mathrm{nm}$ dan dilakukan sebanyak 3 kali pengukuran untuk mengetahui kadar timbal dalam sampel.

\section{HASIL DAN PEMBAHASAN}

Penentuan cemaran timbal dalam maskara ini dilakukan dengan menggunakan Spektrometer Serapan Atom karena alat ini sensitif dan spesifik [8]. Selain itu, sampel akan menjalani proses atomisasi di mana sampel berubah menjadi bentuk uap atom sehingga logam dapat dideteksi dengan baik. Sampel diambil secara acak dari beberapa toko di pasar lokal Kiaracondong yang diharapkan mewakili produk yang akan diamati. Ada 2 jenis 
variasi sampel, yaitu merek terkenal (FB) dan merek tidak terkenal (UFB). Masing-masing variasi ini diambil 3 merek berbeda, seperti dituliskan pada Tabel 1.

Tabel 1. Kode sampel

\begin{tabular}{cc}
\hline Sampel & Kode \\
\hline Merk terkenal & $\mathrm{FB}_{1}$ \\
& $\mathrm{FB}_{2}$ \\
& $\mathrm{FB}_{3}$ \\
\hline Merk tidak terkenal & $\mathrm{UFB}_{1}$ \\
& $\mathrm{UFB}_{2}$ \\
& $\mathrm{UFB}_{3}$ \\
\hline
\end{tabular}

Sampel maskara dibuat menjadi larutan bening menggunakan metode destruksi kering. Destruksi kering adalah metode yang dilakukan dengan memanaskan sampel dalam wadah terbuka. Destruksi kering ini adalah perubahan logam organik dalam sampel menjadi logam anorganik dengan cara menggunakan suhu pemanasan tertentu tergantung pada sampel yang akan dianalisis, dengan tujuan memutus ikatan kovalen antara zat organik dan logam timbal. Sampel yang dianalisis adalah sediaan kosmetik maskara. Penghancuran sampel kering berdasarkan SNI no 6989.8:2009 [9]. Penambahan larutan $\mathrm{HCl}$ ini bertujuan untuk melarutkan logam berat dalam sampel yang mengubah larutan sampel menjadi coklat dan mengeluarkan gas $\mathrm{H}_{2}$ yang ditandai dengan gelembung gas selama proses pemanasan kembali menjadi bentuk karamel. Lalu, ada penambahan larutan $\mathrm{HNO}_{3}$ yang bertujuan untuk melarutkan logam-logam berat baik timbal yang belum larut dengan larutan $\mathrm{HCl}$ dan memutuskan ikatan kovalen. Sampel yang telah mengalami proses pemanasan dan penambahan zat pengoksidasi kemudian disaring menggunakan kertas Whatman untuk mendapatkan larutan yang bening dari hasil penghancuran.

Pembuatan larutan standar timbal harus dilakukan dengan hati-hati agar data yang dihasilkan dapat akurat dan kuantitatif serta menghindari kesalahan. Pengukuran penyerapan kurva kalibrasi menggunakan panjang gelombang spesifik sesuai dengan logam berat yang akan dianalisis, untuk logam berat timbal menggunakan panjang gelombang 283,3 nm. Kurva kalibrasi timbal dapat dilihat pada Gambar 1. Koefisien korelasi mendekati 1 menunjukkan bahwa garis yang hampir lurus terbentuk sehingga dapat dikatakan bahwa kurva membentuk hubungan linier yang ideal.

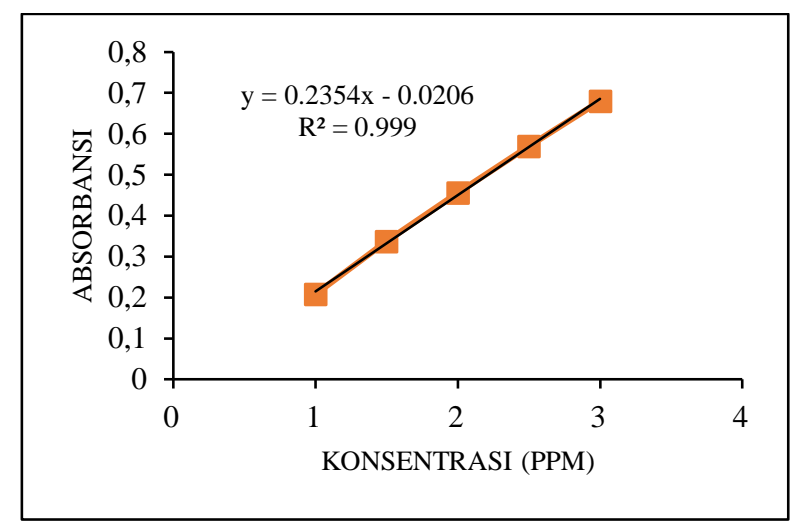

Gambar 1. Kurva kalibrasi timbal.

Pengukuran kadar logam timbal terdeteksi di sejumlah sampel merek terkenal dan merek tidak terkenal, yaitu FB1, FB2, UFB1 dan UFB2 sedangkan di FB3 dan UFB3 tidak ada logam timbal yang terdeteksi dalam sampel. Hasil pengukuran dapat dilihat pada Gambar 2 di bawah ini.

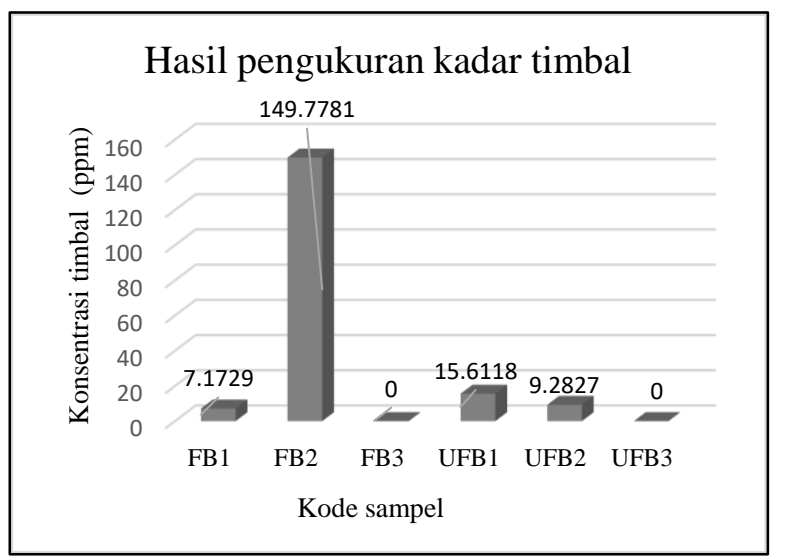

Gambar 2. Kadar timbal pada maskara merek terkenal dan tidak terkenal.

Menurut Peraturan Kepala Badan Pengawas Obat dan Makanan Indonesia (BPOM RI) pada tahun 2011 bahwa batas kontaminasi logam timbal dalam kosmetik tidak melebihi $20 \mathrm{mg} / \mathrm{L}$ [5]. Berdasarkan hasil pengukuran kadar timbal logam dalam penelitian ini, ada dua sampel merek terkenal yang mengandung logam timbal positif dengan kadar 7,1729 mg/L dan 149,7781 mg/L. Sampel FB2 mengandung logam timbal yang melebihi ambang batas. . Sampel maskara merek tidak terkenal diperoleh 2 sampel positif yang mengandung logam timbal dengan kadar 15,6118 $\mathrm{mg} / \mathrm{L}$ dan 9,2827 mg/L. Namun, dua sampel positif masih dalam batas aman karena kadarnya masih di bawah $20 \mathrm{mg} / \mathrm{L}$. 


\section{SIMPULAN}

Hasil pengukuran kadar timbal dalam maskara yang berasal dari pasar lokal kiaracondong, didapatkan 2 sampel merek terkenal dan 2 sampel merek tidak terkenal secara positif mengandung logam berat. Satu dari dua sampel positif pada kosmetik yang merupakan merek terkenal mengandung kadar timbal yang melebihi batas maksimum kontaminasi, yang melebihi $20 \mathrm{mg} / \mathrm{L}, 2$ sampel positif lainnya adalah kosmetik dari merek tidak terkenal, meskipunmasih dalam batas aman.

\section{UCAPAN TERIMA KASIH}

Penulis mengucapkan terima kasih kepada Sekolah Tinggi Farmasi Bandung atas bantuan dana penelitian tahun 2107.

\section{REFERENSI}

[1] ASEAN Cosmetic Directive (ACD), “ASEAN definition of cosmetics and illustrative list by category of cosmetic products", 2008.

[2] W.R. Mindak, "Survey of cosmetics for arsenic, cadmium, chromium, cobalt, lead, mercury, and nickel content", Journal of Cosmetic Science, 2014.

[3] Lawrence, W.M.D., "Toxic metals, the center for development. retrieved from: http://drlwilson.com/articles/TOXIC\%20MET ALS.htm", 2012. (diakses pada Juni 2019).
[4] Draft Guidance, "Lead in cosmetic lip products and externally applied cosmetics: recommended maximum level guidance for industry", U.S. Department of Health and Human Services Food and Drug Administration Center for Food Safety and Applied Nutrition, 2016.

[5] Badan Pengawas Obat dan Makanan Republik Indonesia, Peraturan Kepala Badan pengawas Obat dan Makanan Republik Indonesia Nomor HK.03.1.23.07.11.6662 Tahun 2011 tentang "Persyaratan cemaran mikroba dan logam berat dalam kosmetika", 2011.

[5] D. Murrell, "Lead poisoning", https://www.healthline.com/health/leadpoisoning, diakses pada 25 Februari 2019.

[6] K. Belay, "Validation of a method for determining heavy metals in some ethiopian spices by dry ashing using atomic absorption spectroscopy", International Journal of Innovation and Applied Studies, ISSN 20289324, 2014.

[7] H. Gunzler dan A. "Williams, Handbook of Analytical Techniques", Wiley-VCH, 2002.

[8] N. Miller, "Hazardous metals in environment", Elsevier, 1992.

[9] BSN, Air dan Air Limbah-Bagian 8: "Cara uji timbal $(\mathrm{Pb})$ secara Spektrofotometri Serapan Atom (SSA)-Nyala", SNI 6989.8:2009. Badan Standardisasi Nasional, Jakarta, 2009, 